\title{
A SEMIEMPIRICAL QUANTUM CHEMISTRY APPROACH TO POSSIBLE STRUCTURES AND ENERGIES OF HYDROGEN ATOMS ADSORBED ON Pt(100) AND Pt(111) CLUSTERS AT A SIMULATED Pt/AQUEOUS ELECTROCHEMICAL INTERFACE
}

\author{
C. F. Zinola and A. J. ArviA* \\ Instituto de Investigaciones Fisicoquimicas Teóricas y Aplicadas (INIFTA), Universidad Nacional de La \\ Plata. Sucursal 4, Casilla de Correo 16, (1900) La Plata, Argentina
}

(Received 10 May 1995; in revised form 29 June 1995)

\begin{abstract}
Extended Hueckel molecular orbital calculations for the adsorption of $\mathbf{H}$-atoms in a simulated aqueous electrochemical environment on $\mathrm{Pt}(111)$ and $\mathrm{Pt}(100)$ clusters were made. Different adsorbate configurations were considered. H-atom adsorption on hollow sites coadsorbed with an on top $\mathrm{OH}$ species for $\mathrm{Pt}(111)$, and $\mathrm{H}$-atom adsorption on bridge sites for $\mathrm{Pt}(100)$ are favoured. At potentials lower than the hydrogen electrode equilibrium potential, $H$-adatom configurations involving subsurface $P t$ atoms can also be formed. For both $\mathrm{Pt}(111)$ and $\mathrm{Pt}(100)$, these structures are probably related to species involved in the $\mathrm{H}$-atom electrosorption and hydrogen evolution reaction. Copyright (C) 1996 Elsevier Science Ltd
\end{abstract}

Key words: hydrogen, platinum, semiempirical methods.

\section{INTRODUCTION}

The $\mathrm{Pt}-\mathrm{H}$ atom interaction plays a key role in electrochemistry, particularly at the $\mathrm{Pt} /$ aqueous solution interface in the range of potentials related to the $\mathrm{H}$ adatom electrosorption equilibria, and hydrogen evolution reaction. Relevant data on these processes have been obtained on $\mathrm{Pt}$ single crystals involving both low and high Miller indices[1-7]. In principle, the formation and characteristics of $\mathrm{H}$-adsorbates on $\mathrm{Pt}$ in a particular environment depend on the $\mathrm{H}$-atom adsorption energy at the different adsorption sites[7-9]. It should be noted that in recent years $\mathrm{Pt}-\mathrm{H}$ and $\mathrm{Pt}-\mathrm{H}_{2} \mathrm{O}$ interactions under ultrahigh vacuum conditions, at well-defined single crystal surfaces, have been extensively studied[1014], and the results obtained for those systems have encouraged us to attempt a quantum mechanics modelling of the $\mathrm{Pt}-\mathrm{H}$ system at the $\mathrm{Pt} /$ aqueous electrochemical interface. In general, two main types of $\mathrm{H}$-adatoms on $\mathrm{Pt}$ in an aqueous environment are distinguished in the range of potentials where the $\mathrm{H}$-atom electrosorption takes place, namely, strongly and weakly bound $\mathrm{H}$-adatoms dominating at $\mathrm{Pt}$ surfaces with a lower and a higher atom density, respectively. However, the real situation is more complex[15-18] as, for instance, the third anodic voltammetric peak related to $\mathrm{H}$-adatom electrodesorption on $\mathrm{Pt}$ has been assigned to subsurface hydrogen adsorption[19]. Furthermore, a.c. impedance data[20,21] have revealed that other $\mathrm{H}$ adatom species would appear as intermediates in the course of the hydrogen evolution reaction on $\mathrm{Pt}$ in

* Author to whom correspondence should be addressed. acid. This conclusion appears to be supported by data derived from electrochemically modulated infrared spectroscopy[22-24] and visible-infrared sum frequency generation techniques[25]. The formation of intermediates in the hydrogen evolution reaction has also been inferred from the analysis of potential relaxation curves $[8,9]$.

The situation outlined above suggested the convenience of attempting a quantum chemistry approach to surface species likely formed at a simulated $\mathrm{Pt}$ / aqueous electrochemical interface in order to discriminate the structure and energy of possible $\mathrm{H}$-adsorbates. This is a relevant issue in dealing with, for instance, the interpretation of the complex electrosorption spectra of $\mathrm{H}$-atoms on $\mathrm{Pt}$ in aqueous solution, and to provide a more realistic approach to the nature of $\mathrm{H}$-atom intermediates involved in the hydrogen evolution reaction.

The possible structures and energies of $\mathrm{H}$-adatoms were calculated on $\operatorname{Pt}(100)$ and $\operatorname{Pt}(111)$ clusters at a simulated $\mathrm{Pt} /$ aqueous electrochemical interface using the Extended Hueckel Molecular Orbital (EHMO) semiempirical procedure developed by Hoffmann[26, 27] and recently improved by Calzafferi[28-31]. This calculation procedure proved to be sufficiently simple and reliable to deal with the subject matter of this paper. In fact, the selection of the calculation procedure was determined by computational limitations and the size of the finite clusters involving transition metal atoms of a high atomic number.

\section{THE CALCULATION PROCEDURE}

The EHMO method was applied to describe the structural and electronic properties of the $\mathrm{Pt}-\mathrm{H}$ 
system for a given geometry. The EHMO method is one of the simplest semiempirical methods available to describe the valence electronic structure, binding energies and chemical properties of large transition metal clusters involved in adsorption systems. It is worth noting that the EHMO method gives an overestimation and an underestimation in bonding forces, but the relative bonding structural stability is well described[28].

The EHMO method including a sum of two body electrostatic terms[27, 30,31] makes possible the optimization of the adsorbate structure for a given geometry. Accordingly, ET, the gobal energy of the system, is calculated from the contribution of three terms, ie

$$
\mathrm{ET}=E_{\mathrm{EHMO}}-\sum_{\mu} b_{\mu}^{0} E_{\mu}^{0}+\mathrm{RE}
$$

where $E_{\text {EHMO }}$ is the non-corrected EHMO total energy including monoelectronic terms; $b_{\mu}^{0}$ is the occupation number, $E_{\mu}^{0}$ is the valence state ionization potential (VSIP) of the $\mu$ th atomic orbital, and RE is the repulsion energy correction term. RE is evaluated from $E_{\mathrm{AB}}$, the contribution of the electrostatic repulsion energy between atoms $A$ and $B$, separated from each other by the distance $R_{\mathrm{AB}}$. Then,

$$
\mathrm{RE}=\sum_{\mathrm{A}} \sum_{\mathrm{B}<\mathrm{A}} E_{\mathrm{AB}}
$$

The EHMO method does not explicitly consider a term for the short-time repulsion energy between different atoms. To calculate the minimum adsorption energy and equilibrium distance between interacting atoms, the method was reformulated[29-31] by including firstly $E_{\mathrm{AB}}$, a repulsion energy term, and secondly, $H_{\mu \nu}$, a distance-dependent exponential factor in the off-diagonal EHMO matrix elements. The former represents the difference between the coulombic interaction energy and the arithmetic mean of attractive interaction energy for $\mathrm{A}-\mathrm{B}$ and B-A. Then,

$$
\begin{aligned}
E_{\mathrm{AB}}= & \frac{Z_{\mathrm{A}} Z_{\mathrm{B}}}{R_{\mathrm{AB}}} \\
& -\frac{1}{2}\left[Z_{\mathrm{A}} \int \frac{\rho_{\mathrm{B}}(\bar{r})}{\left|R-\bar{r}_{\mathrm{A}}\right|} \mathrm{d} \bar{r}+Z_{\mathrm{B}} \int \frac{\rho_{\mathrm{A}}(\bar{r})}{\left|R-\bar{r}_{\mathrm{B}}\right|} \mathrm{d} \bar{r}\right]
\end{aligned}
$$

where $Z_{\mathrm{i}}, R_{\mathrm{i}}$ and $\rho_{\mathrm{i}}$ are the nuclear charge, the location and the electron density of the $i$ th atom $(i=\mathrm{A}$, $B$ ), in this case atom $B$ being more electronegative than atom $A$. The latter is calculated from the empirical weighted Wolfsberg-Helmholtz formula,

$$
H_{\mu v}=\frac{1}{2} K_{\mathrm{AB}}\left(H_{\mu \mu}+H_{v v}\right) S_{\mu v}
$$

where $\mu$ and $\nu$ stand for the $\mu$ th and the $v$ th orbitals of atoms A and B, respectively.

Values of the diagonal elements for the Hamiltonian in equation (4) are experimentally based, and valence orbitals are given by the Slater form. $K_{\mathrm{AB}}$ and $\delta$ are adjustable empirical parameters in the range $1.4 \leqslant(1+\kappa) \leqslant 2.5$ and $0 \leqslant \delta \leqslant 0.1 \mathrm{~nm}$. Then, $K_{\mathrm{AB}}$ is the $K$-parameter used for the EHMO method in the off-diagonal Hamiltonian matrix elements,

$$
K_{\mathrm{AB}}=1+\kappa \exp \left[-\delta\left(R_{\mathrm{AB}}-r_{0}\right)\right]
$$

where $r_{0}$ is the sum of atomic radii of atoms $A$ and B. The diagonal Hamiltonian matrix elements are given by the - VSIP values taken from experimental and Hartree-Fock-Slater data. Slater's exponents are based on self-consistent calculations.

The following calculation procedure was employed to evaluate the interaction of a single $\mathrm{H}$-atom with either the $\mathrm{Pt}(111)$ or $\mathrm{Pt}(100)$ single crystal surface in a simulated aqueous electrochemical environment, under an applied electric potential. The single $\mathrm{H}-\mathrm{Pt}$ interaction is described by an adsorbed ensemble of the type $\left[\mathrm{Pt}_{N} \cdot H\right]$, where $N$ is the number of $\mathrm{Pt}$ atoms of the high spin bilayer cluster used to model the $\mathrm{Pt}$ surface (Fig. 1). For $P t(111)$ and $P t(100)$ the values $N=22$ and 25 were chosen, respectively. These figures represent the minimum values of $N$ compatible with border effectfree calculations and constant binding energies. Clusters were geometrically built by keeping the $\mathrm{Pt}-\mathrm{Pt}$ bond length constant at $0.277 \mathrm{~nm}$. This figure agrees with the Pt-Pt interatomic distance in bulk Pt[32].

The $\mathrm{H}-\mathrm{Pt}$ interaction energy is given by the specific VSIP value which defines the equilibrium potential of the system. This value is attained when the charge transfer at the equilibrium internuclear distance is close to that predicted from the electronegativity difference according to the Pauling's ionicity relationship[33]. Values of the initial parameters are assembled in Table 1, which was taken from[34].

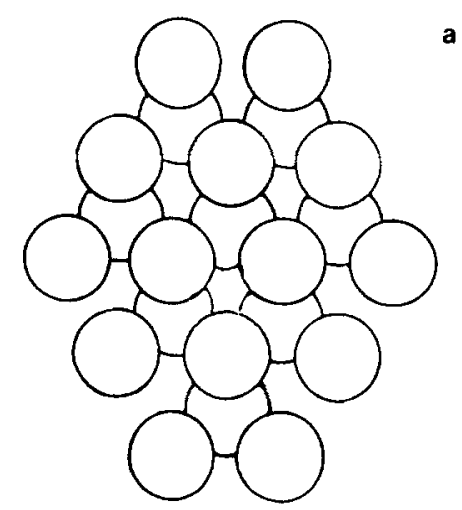

b

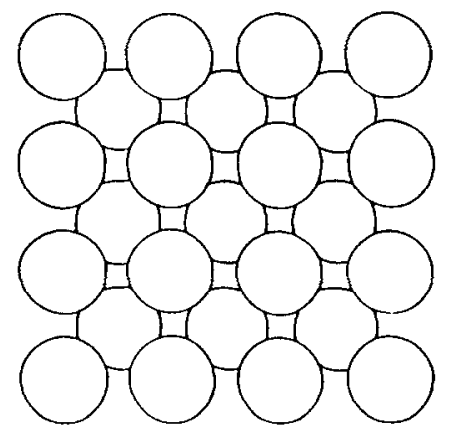

Fig. 1. Platinum cluster models. (a) $\mathrm{Pt}_{22}$ (111); (b) $\mathrm{Pt}_{25}(100)$. Complete and uncomplete circles indicate $\mathrm{Pt}$ atoms at the surface and subsurface layer, respectively. 
Table 1. EHMO calculations: optimized parameters

\begin{tabular}{cccccc}
\hline Atomic orbital & VSIP(eV) & $\zeta_{1}\left(\right.$ a.u. $\left.^{-1}\right)$ & $\zeta_{2}$ (a.u. $\left.^{-1}\right)$ & $c_{1}$ & $c_{2}$ \\
\hline Pt 5d & -12.83 & 4.0950 & 1.8600 & 0.7980 & 0.3520 \\
Pt 6s & -9.32 & 1.9830 & & & \\
Pt 6p & -5.72 & 1.3440 & & & \\
O 2s & -27.96 & 2.5640 & & & \\
O 2p & -12.16 & 2.2640 & & & \\
H 1s & -13.30 & 1.3000 & & & \\
\hline
\end{tabular}

VSIP $\equiv$ Valence state ionization potential.

$\zeta_{1,2} \equiv$ Exponents of the base generating functions.

$c_{1,2} \equiv$ Linear coefficients of the double zeta Pt $d$-orbitals.

Following the method previously described for $\mathrm{Pt}$ and $\mathrm{H}[35]$, VSIP and Slater orbital exponents were taken from[28]. Values $\delta=0.035 \mathrm{~nm}$ and $K_{\mathrm{AB}}=$ 1.75 have been set in equation (5) as those leading to the best description of both the bond length and the adsorption energy.

Positive applied electric potentials were simulated by shifting VSIP values from the Fermi energy level of $\mathrm{Pt}$ downwards[36, 37]. The influence of the applied electric potential on solvent adsorption was neglected. In a previous study[34], the change of VSIP with the applied electric potential was set equal to 1 as the simplest choice, because there was no experimental information that could justify a different dependence. On the other hand, for the $\mathrm{H}$-atom electrosorption on $\mathrm{Pt}$, it is reasonable to admit that the change in the geometry of the $\mathrm{H}$ adsorbate ensemble with the applied electric potential is reflected by the characteristics of $\mathrm{H}$-atom electrosorption voltammetric current peaks.

For a single $\mathrm{H}$-adatom and a single water molecule interaction with the $\mathrm{Pt}$ single crystal surface, distinguishable adsorption sites, such as, on-top (one-fold), bridge (two-fold) and hollow (higher coordination) were considered. Adsorption at a hollow site implies a four-fold coordination on $\mathrm{Pt}_{25}(100)$. Otherwise, either three or four $\mathrm{Pt}$ atoms can define the hollow $\mathrm{H}$-atom or $\mathrm{OH}$ coordination on $\mathrm{Pt}_{22}$ (111), depending on whether the fcc [(3-1)hollow site] or the hcp [(3-3)-hollow site] local symmetry is involved, respectively. Obviously, several adsorption configurations are related to the interaction of either a single $\mathrm{H}$-atom or $\mathrm{OH}$-species with each one of those sites. In this work, different adsorption configurations and degrees of Pt surface coverage by $\mathrm{H}$-atoms on both the top-most and underlying sites were systematically considered. In this case, the most stable $\mathrm{OH}$-adsorbate configuration was chosen.

It should be noted that the similarities between theoretical calculations and real surface processes must be handled carefully because of the space limitation of finite clusters which can lead to different responses of the electronic distribution to a local interaction with small atoms. Unfortunately, it is difficult to extend ab-initio calculations, as those carried out for small $(N=4,5)$ "testing" clusters[38], to large clusters $(N>20)$ built up with transition metals of high atomic numbers. In these cases EHMO calculations lead to results which can be compared with experimental data[27, 28, 34, 36, 37].

\section{RESULTS}

The formation of a stable $\mathrm{H}$-adatom configuration implies that a minimum potential energy for the system is achieved. In the simulated aqueous electrochemical environment, calculations show that among all possible $\mathrm{H}$-adatom configurations, those involving the bridge on $\mathrm{Pt}(100)$, and the hollow coordination together with neighbour $\mathrm{H}_{2} \mathrm{O}$ or $\mathrm{OH}$-adsorbates on $\mathrm{Pt}(111)$ are the most relevant. From spectroscopic data[23, 24] it was found that $\mathrm{H}$-adatom bridge coordination for $\mathrm{Pt}_{25}(100)$, and (3-1)-hollow coordination with neighbour on top $\mathrm{OH}$-adsorbates for $\mathrm{Pt}_{22}(111)$ are the most stable adsorbate configurations, in agreement with a full optimization in bond distance and planar angle for each adsorbate geometry (Fig. 2). The geometry and relative stability of each adsorbate can be inferred from data assembled in Table 2. Values of AE, the adsorption energy, were calculated from the difference:

$$
\mathrm{AE}=E_{\mathrm{T}, \mathrm{PtNH}_{\mathrm{H}}}-E_{\mathrm{T}, \mathbf{P}_{\mathrm{N}}}-E_{\mathrm{H}}-E_{\mathrm{OH}}
$$

where $E_{\mathrm{T}, \mathrm{P}_{\mathrm{N} H}}$ and $E_{\mathrm{T}, \mathrm{P}_{N},}$ are the total energy for the $\left[\mathrm{Pt}_{N} \cdot \mathrm{H}\right]$ and the $\left[\mathrm{Pt}_{N}\right]$ ensembles, respectively, $E_{\mathrm{H}}$ and $E_{\mathrm{OH}}$ stand for the energy term related to the free $\mathrm{H}$-atom and $\mathrm{OH}$-species, respectively.

The geometry optimization of adsorbed ensembles is obtained by changing simultaneously $r_{\mathrm{P} 1-\mathrm{H}}$, the $\mathrm{Pt}-\mathrm{H}$ bond distance and the $\mathrm{Pt}-\mathrm{Pt}-\mathrm{H}$ planar

Table 2. Single atomic $H$ adsorption energy, AE, optimized $\mathrm{Pt}-\mathrm{H}$ distance, and perpendicular distance (h) from $\mathrm{H}$-atom to the plane of the surface for $\left[\mathrm{Pt}_{22}(111) \cdot \mathrm{H} \cdot \mathrm{OH}_{2}\right]$ and $\left[\mathrm{Pt}_{25}(100) \cdot \mathrm{H}\right]$ configurations at the equilibrium potential

\begin{tabular}{|c|c|c|c|}
\hline $\mathrm{Pt}_{22}(111)$ & $\begin{array}{l}\mathrm{AE} \\
\mathrm{eV}\end{array}$ & $\begin{array}{c}r_{\mathrm{Pt}-\mathrm{H}} \\
\mathrm{nm}\end{array}$ & $\begin{array}{c}h \\
\mathrm{~nm}\end{array}$ \\
\hline on-top & 0.0234 & 0.174 & - \\
\hline bridge & 0.1239 & 0.180 & 0.104 \\
\hline $\begin{array}{r}\text { hollow } \\
(3-3)\end{array}$ & 0.0786 & 0.175 & 0.020 \\
\hline $\begin{array}{l}\text { hollow } \\
(3-1)\end{array}$ & -0.8310 & 0.186 & 0.095 \\
\hline $\mathrm{Pt}_{25}(100)$ & $\begin{array}{l}\mathrm{AE} \\
\mathrm{eV}\end{array}$ & $\underset{\mathbf{n m}}{r_{\mathrm{Pl}-\mathrm{H}}}$ & $\begin{array}{c}h \\
\mathrm{~nm}\end{array}$ \\
\hline on-top & 0.0126 & 0.176 & $\ldots$ \\
\hline bridge & -0.7831 & 0.187 & 0.112 \\
\hline hollow & 0.0663 & 0.175 & 0.020 \\
\hline
\end{tabular}




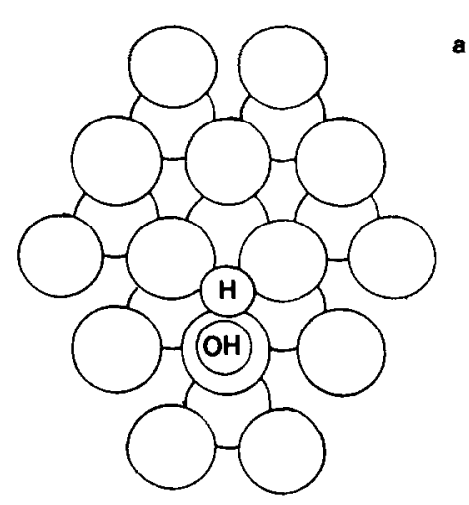

b

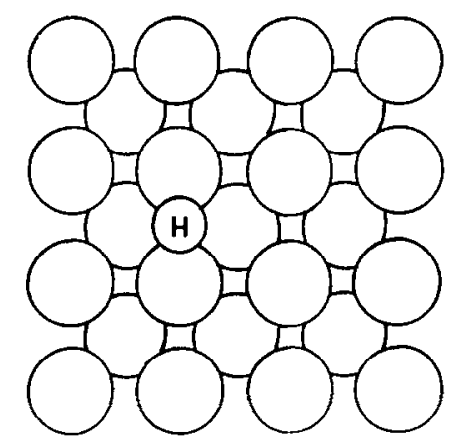

Fig. 2. H-atom structures involving surface $\mathrm{Pt}$ atoms at $\mathrm{Pt}$ clusters. (a) H-adatom (3-1)-hollow coordination and $\mathrm{OH}$ adsorbate on-top coordination on $\mathrm{Pt}_{22}(111)$. (b) $\mathrm{H}$-adatom bridge coordination on $\mathrm{Pt}_{25}(100)$.

angle. For this purpose, $r_{\mathrm{Pt}-\mathrm{H}}$ was changed $0.001 \mathrm{~nm}$ stepwise from the initial $r_{\mathbf{P t}-\mathbf{H}}=0.160 \mathrm{~nm}$ value up to a value at which the $\mathrm{Pt}-\mathrm{H}$ bond rupture occurs. Correspondingly, for each $r_{\mathrm{Pt}-\mathrm{H}}$ value the planar angle was fully optimized. The same geometry optimization was extended to the $\mathrm{Pt}-\mathrm{O}-\mathrm{H}$ bonds.

The adsorption bond resulting from the $\mathrm{H}-\mathrm{Pt}$ interaction at the second $\mathrm{Pt}$ layer is similar to that previously calculated from a linear $\mathrm{H}-\mathrm{Pt}$ coordination. No influence on the adsorption energy was found when larger Pt clusters were considered.

Data assembled in Table 2 show that the most stable structure of a single $\mathrm{H}$-adatom on $\mathrm{Pt}_{25}(100)$ corresponds to the bridge adsorbate geometry, whereas for a single $\mathrm{H}$-adatom on $\mathrm{Pt}_{\mathbf{2 2}}(111)$ the largest adsorbate stabilization energy results for the (3-1)-hollow interaction with a neighbour on top OH-adsorbate $\left(r_{\mathrm{Pt}_{-} \mathrm{O}}=0.202 \mathrm{~nm}, r_{\mathrm{O}_{-\mathrm{H}}}=0.102 \mathrm{~nm}\right)$. These results are rather different from those reported previously[37], since for the chosen parameters, $\mathrm{OH}$ species are more likely to be adsorbed than a single water molecule.

The gradual Pt surface coverage by $\mathrm{H}$-adatoms makes the adsorbate ensemble more stable on both $\mathrm{Pt}_{25}(100)$ and $\mathrm{Pt}_{22}(111)$ surfaces. It should be noted, however, that EHMO calculations made for water adsorption on $\mathrm{Pt}_{25}(100)$ results in an unstable adsorbate for $\mathrm{Pt}$ fully covered by $\mathrm{H}$-adatoms. These results are consistent with the $\mathrm{H}$-adatom structures advanced over a decade ago for Pt from in situ infrared spectroscopy $[22,24]$.
The net charge variation in the $\mathrm{H}$ - and $\mathrm{O}$-atom for the (3-1)-hollow adsorption with the applied electric potential was followed on $\mathrm{Pt}_{22}(111)$. In this case, it was found that the $\mathrm{O}$-atom charge strongly depends on the applied electric potential, since the $\mathrm{O}$-atom is directly bonded to the Pt surface. On the other hand, the net charge on the $\mathrm{H}$-atom bonded to the $\mathrm{O}$-atom is almost constant in the range -1.0 to $1.0 \mathrm{eV}$, since the $\mathrm{H}$-atom bound to the $\mathrm{O}$-atom is located far from the Pt surface (Table 3). Likewise, no clear variation in the charge of the $\mathrm{H}$-atom bonded to $\mathrm{Pt}$ with the applied electric potential could be observed (Table 3). These results indicate that the influence of the applied electric potential on the Pt surface is almost fully compensated by the more electronegative $\mathrm{O}$-atom.

When the degree of surface coverage by $\mathrm{H}$ adatoms increases, new stable $\mathrm{H}$-adatom structures which are built at the centre of a four $\mathrm{Pt}$ atom cluster region, are found for both $\mathrm{Pt}_{22}(111)$ and $\mathrm{Pt}_{25}(100)$. The calculation of the stability of these structures is appropriate to describe possible $\mathrm{H}$ adatom local interactions resulting from different degrees of $\mathrm{Pt}$ surface coverage. For the most stable $\mathrm{H}$-adatom bridge configuration on $\mathrm{Pt}_{25}(100)$ (Fig. 3), the stabilization of the adsorbed ensemble proceeds via a $(2 \times 2)$-structure at a bridge coordination site, whereas for $\mathrm{Pt}_{22}(111)$ (Fig. 4) the adsorbed ensemble energy is $-0.13 \mathrm{eV}$, as would be expected for a physisorbed species. However, a $\mathrm{H}$-adatom at a (3-1)hollow site, together with an $\mathrm{OH}$-adsorbate at an on-top neighbour site, gives a more realistic description of the $\mathrm{H}$ adsorbed ensemble.

Different local interactions and changes in the $\mathrm{H}$ adatom adsorption energy on $\mathrm{Pt}_{25}(100)$ are obtained at negative applied electric potentials. Likewise, the

Table 3. Charges on the $\mathrm{O}$ and $\mathrm{H}, q_{\mathrm{O}}$ and $q_{\mathrm{H}}$, of hollow $\left[\mathrm{Pt}_{22}(111) \cdot \mathrm{H} \cdot \mathrm{OH}_{2}\right]$ ensembles at different applied electric potential (V)

\begin{tabular}{crlrrr}
\hline $\mathrm{V}(\mathrm{eV})$ & 1.0 & 0.5 & \multicolumn{1}{c}{0} & \multicolumn{1}{c}{-0.5} & -1.0 \\
\hline $\mathrm{q}_{\mathrm{o}}(\mathrm{ecu})$ & 0.589 & 0.546 & -0.501 & -0.456 & -0.406 \\
$q_{\mathrm{Ho}}{ }^{*}(\mathrm{ecu})$ & 0.404 & 0.405 & 0.408 & 0.408 & 0.408 \\
$q_{\mathrm{H}}+(\mathrm{ecu})$ & -0.204 & 0.112 & -0.073 & -0.012 & 0.045 \\
\hline
\end{tabular}

* Net charge on the $\mathrm{H}$-atom bound to $\mathrm{O}$-atom.

+ Net charge on the $\mathrm{H}$-atom bound to $\mathrm{Pt}$.

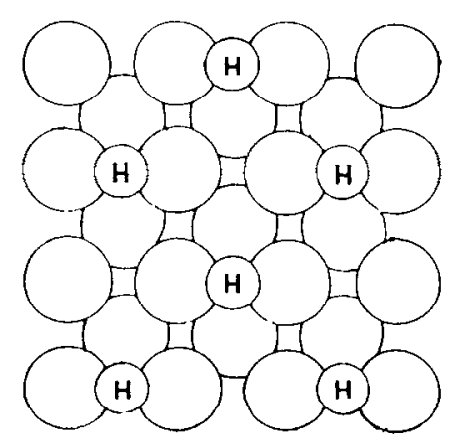

Fig. 3. H-adatom structures involving surface $\mathbf{P t}$ atoms at $\mathrm{Pt}$ clusters. H-adatom bridge coordination on $\mathrm{Pt}_{25}(100)$ for a degree of surface coverage $\cong 3 / 8$. 


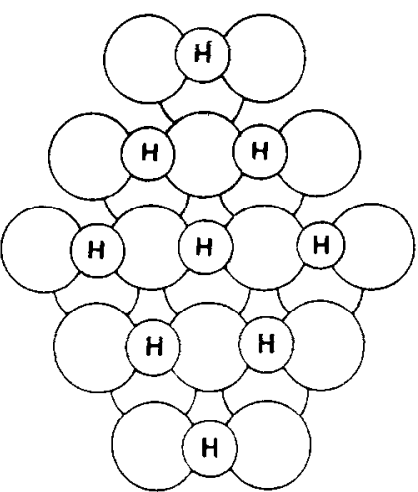

Fig. 4. H-adatom structures involving surface $P t$ atoms at $\mathrm{Pt}$ clusters. H-adatom bridge coordination on $\mathrm{Pt}_{22}(111)$ for a degree of surface coverage $\cong 9 / 14$.

presence of a $\mathrm{H}$-adatom at a hollow site directly bonded to a Pt-atom at the second layer, tends to shift the $\mathrm{H}$-adatom from a bridge to an on-top site. Although the appearance of such complex geometry is rather unlikely $(0.23 \mathrm{eV})$, it tends to become stable when the applied electric potential is below $-0.1 \mathrm{eV}$. This type of $\mathrm{H}$-adatom coordination involving both the first and second $\mathrm{Pt}$ atom layer for $\mathrm{Pt}_{25}(100)$ is depicted in Fig. 5. Nevertheless, for applied electric potentials more negative than $-0.35 \mathrm{eV}$, the stabilization of the $\mathrm{H}$-adatom adsorbed ensemble decreases abruptly, and for $-0.4 \mathrm{eV}$ only physisorbed $\mathrm{H}$-atom species are observed again on $\mathrm{Pt}_{25}(100)$. For applied potentials even lower than $-0.4 \mathrm{eV}$, negative net charges for $\mathbf{H}$ - and Pt-atoms are found. Correspondingly, a large repulsion energy between $\mathrm{Pt}$ and $\mathrm{H}$ atoms, which can not be compensated by the adsorption energy itself, appears.

A similar analysis was made for $\mathrm{H}$-adatoms on $\mathrm{Pt}_{22}$ (111). In this case, a $\mathrm{H}$-adatom at a (3-1)-hollow site and an $\mathrm{OH}$-adsorbate at a neighbour on-top site become the most likely adsorbate ensemble (Fig. 6), although values of $\mathrm{AE}$ correspond to physisorbed species when the applied electric potential is above $-0.15 \mathrm{eV}$. On the other hand, for applied electric potentials below $-0.35 \mathrm{eV}$, a further stabilization of the $\mathrm{H}$-adatom interacting with a $\mathrm{Pt}$ atom at the second layer is observed. In this case, the corre-

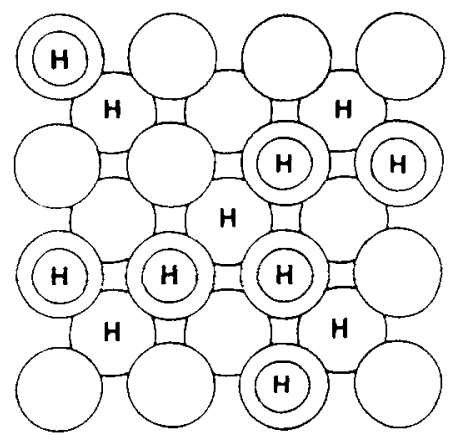

Fig. 5. H-adatom structures involving subsurface $\mathrm{Pt}$ atoms at $\mathrm{Pt}$ clusters. H-adatom on-top coordination on $\mathrm{Pt}_{25}(100)$. Degree of surface coverage $\cong 7 / 16$; degree of suburface coverage $\cong 5 / 9$. H-atoms with and without a circle represent $\mathrm{H}$-atoms interacting with either a surface $\mathrm{Pt}$ or a subsurface $\mathrm{Pt}$ atom, respectively.

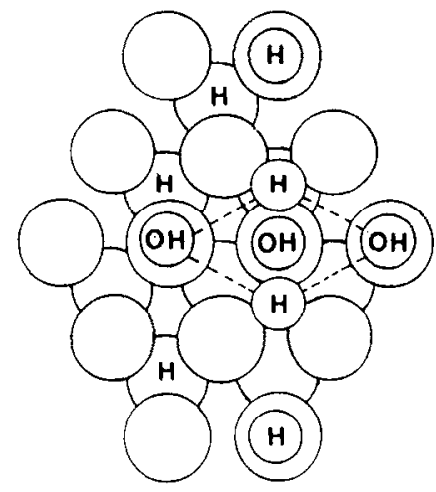

Fig. 6. H-adatom structures involving subsurface $\mathrm{Pt}$ atoms at $\mathrm{Pt}$ clusters. $\mathrm{H}$-adatom bridge and on-top coordination on $\mathrm{Pt}_{22}(111)$. Degree of surface coverage $\cong 2 / 7$; degree of surface coverage $\cong 3 / 8$. On-top coordinated neighbour $\mathrm{OH}$-adsorbates are also shown.

sponding $A E$ value is free from the water coadsorption influence.

For applied electric potentials below $-0.5 \mathrm{eV}$ the adsorbate ensemble is no longer stable, ie the $\mathrm{AE}$ changes from negative to positive. This change is due to a rather large net negative charge for both the $\mathrm{H}$ and $\mathrm{Pt}$ atom on $\mathrm{Pt}_{22}(111)$.

The above description resulting from EHMO calculations implies the possible existence of several $\mathbf{H}$ adatom states on $\mathrm{Pt}$ in the simulated aqueous electrochemical interface. In fact, the multiplicity of $\mathrm{H}$-atom electrosorption voltammetric peaks has been associated with the formation of different $\mathrm{H}$ adatoms on Pt in acid. The EHMO description also indicates that, under a high degree of surface coverage by $\mathbf{H}$-atoms, $\mathbf{H}$-adsorbates involving a $\mathbf{P t}$ atom at the second layer would be also possible.

\section{DISCUSSION}

It is well known that $\mathrm{H}$-atom electroadsorption on Pt results mainly in the formation of two different adsorbates, namely, the weakly and strongly adsorbed $\mathrm{H}$-atom. For $\mathrm{Pt}(111)$ single crystal surfaces, the weak $\mathrm{H}-\mathrm{Pt}$ bonding, in contrast to the strong H-Pt bonding for $\mathrm{Pt}(100)$, should involve the contribution of a water molecule to the formation of the adsorbed ensemble[37, 39-42], which can be formally represented as a $\left[\mathrm{Pt}_{N} \cdot \mathrm{H} \cdot \mathrm{OH}_{2}\right]$ ensemble. $I R$ spectroscopy data showed that the bond energy of weakly bound $\mathrm{H}$-adatoms on $\mathrm{Pt}(111)$ depends on the applied electric potential (charge density) $[13,39]$. Otherwise, strongly bound $\mathrm{H}$-adatoms on $\mathrm{Pt}(100)$ imply an adsorbed ensemble in which the $\mathrm{H}$-atom electron density is delocalized on the Pt surface[37].

Depending on whether the electron energy level is lower or higher than the Pt Fermi level, either negatively or positively charged $\mathrm{H}$-adatoms result. This excess of charge results in a change in the shape of the potential energy curves, which in turn implies a change in both the $\mathrm{H}-\mathrm{Pt}$ site interaction for each possible $\mathrm{H}$-adatom coordination, and the poiarization of molecules at the interface.

Our results show that the formation of $\mathrm{H}$ adsorbates at surface $P t$ sites and subsurface $P t$ sites 
in the simulated aqueous electrochemical environment becomes possible on both $\mathrm{Pt}_{22}(111)$ and $\mathrm{Pt}_{25}(100)$. Furthermore, results predict that a transition from surface to subsurface adsorbate configurations is feasible by adequately changing the applied electric potential. This finding provides a new insight into the nature of $\mathrm{H}$-adatom species on $P t$ in both vacuum and aqueous environments. In fact, this type of configurational transition has been reported for $\operatorname{Pd}(111)[43]$, and the presence of subsurface $\mathrm{H}$-adatom states at $\mathrm{Pt}, \mathrm{Pd}$ and $\mathrm{Ni}$ single crystal electrodes as well $[44,45]$.

$\mathrm{H}$-adatom subsurface states on $\mathrm{Pt}$ result from the $\mathrm{H}$-adatom stabilization by an excess of negative surface charge which favours a transition from a $\mathrm{H}$ adatom bridge coordination to a $\mathrm{H}$-adatom hollow subsurface coordination on $\mathrm{Pt}_{25}(100)$, and from a $\mathrm{H}$ adatom (3-1)-hollow coordination to a $\mathrm{H}$-adatom hollow subsurface coordination on $\mathrm{Pt}_{22}$ (111) (Figs 5 and 6). $\mathrm{H}$-adatoms bound to a surface $\mathrm{Pt}$ and a subsurface $\mathrm{Pt}$ atom are electronically different as a result of the excess of negative charge at the $\mathrm{H}$-adatom bound to a subsurface $\mathrm{Pt}$ atom. These $\mathrm{H}$-adatom subsurface states could probably be related to the $\mathrm{Pt}-\mathrm{H}$ vibration frequency recorded near $0.05 \mathrm{~V}$ by electrochemically modulated infrared spectroscopy[22] and visible-infrared sum frequency generation vibrational spectroscopy[25].

On the other hand, the possible existence of $\mathrm{H}$ adatoms at the subsurface level would introduce an additional state in those electrochemical processes in which $\mathrm{H}$-atoms are involved. This can be visualized through the potential energy curves calculated from Morse equation[46] for the solvated proton (reactant) and the $\mathrm{H}$-adatom bound to surface and subsurface $\mathrm{Pt}$ atoms (product) (Fig. 7). For this purpose, data assembled in Table 4 were used for the $\mathrm{H}$-surface and $\mathrm{H}$-subsurface adsorbates in the course of the $\mathrm{H}^{+}$ion discharge step.

The potential energy vs. either the $r_{\mathrm{Pt}-\mathrm{H}}$ or $r_{\mathrm{H}-\mathrm{OH}_{2}}$ distance (Fig. 7) plot represents the stabilization for the $\mathrm{H}_{3} \mathrm{O}^{+}$ion in solution (curve 1), the $\mathrm{H}$-adatom bound to a surface $\mathrm{Pt}$ atom (curve 2), and the $\mathrm{H}$ adatom bound to a subsurface $\mathrm{Pt}$ atom (curve 3 ). The equilibrium $\mathrm{Pt}-\mathrm{H}$ bond length is taken from the gas phase data, $r_{\mathrm{Pl}_{-H}}=0.18 \mathrm{~nm}$ [36]. The equilibrium distance in curve 1 is $0.22 \mathrm{~nm}$, irrespective of the applied electric potential. For $\mathrm{H}$-adatom formation on $\mathrm{Pt}$ two equilibrium distances are obtained, namely, $0.18 \mathrm{~nm}$ and $0.16 \mathrm{~nm}$, depending on whether a $\mathrm{Pt}$ atom at the surface or at the subsurface is involved in adsorbate formation.

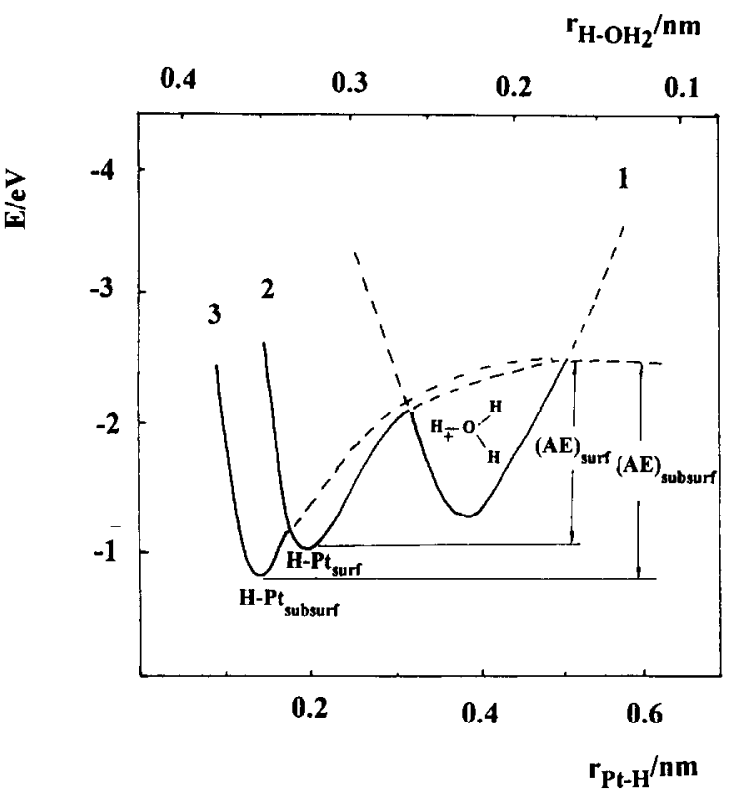

Fig. 7. Potential energy vs. $r_{\mathrm{Pt}-\mathrm{H}}$ and $r_{\mathrm{H}-\mathrm{OH}_{2}}$ diagram involving $\mathrm{H}^{+}$-ion hydration (curve 1), $\mathbf{H}$-adatom-surface $\mathrm{Pt}$ (curve 2) and $\mathrm{H}$-adatom-subsurface $\mathrm{Pt}$ (curve 3) interactions. Calculations are based on data assembled in Table 4.)

The preceding description can be further improved by considering the change of the substrate lattice spacing with the applied potential, which is another problem of importance in dealing with electrochemically promoted $\mathrm{H}$-absorption on metals[15].

\section{CONCLUSIONS}

- The EHMO quantum chemistry approach applied to the reversible $\mathrm{H}$-atom electrosorption provides information about the possible existence of a $\mathrm{H}$ adatom and $\mathrm{OH}$-species bound to a surface $\mathrm{Pt}$ atom, and a $\mathrm{H}$-adatom bound to a subsurface $\mathrm{Pt}$ atom.

- For $\mathrm{Pt}_{22}(111)$ the stable $\mathrm{H}$-adatom ensemble involving surface $\mathrm{Pt}$ comprises a (3-1)-hollow coordination and an on-top neighbour $\mathrm{OH}$-adsorbate, whereas for $\mathrm{Pt}_{25}(100)$ the stable $\mathrm{H}$-adatom ensemble consists of a bridge coordination.

- For $\mathrm{Pt}_{22}(111)$ the stable $\mathrm{H}$-adatom ensemble involving subsurface $\mathrm{Pt}$ can be described as a (3-1)hollow surface and (3-3)-hollow subsurface coordi-

Table 4. Parameters used in the calculation of the potential energy diagram shown in Fig. 7[46]

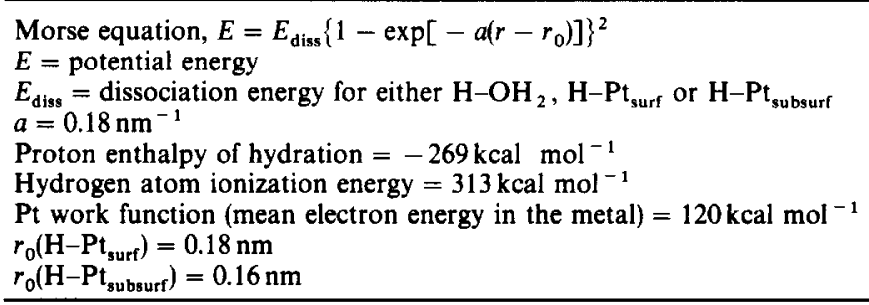


nation with $\mathrm{OH}$-adsorbates as neighbours at on-top sites. Otherwise, for $\mathrm{Pt}_{25}(100)$ the stable $\mathrm{H}$-adatom ensemble implies a hollow subsurface and an on-top surface coordination, without $\mathrm{OH}$-adsorbates.

- Morse potential energy curves for proton in solution, a $\mathrm{H}$-adatom bound to a surface $\mathrm{Pt}$ atom, and a $\mathrm{H}$-adatom bound to a subsurface $\mathrm{Pt}$ atom indicate that within the range 0 to $-0.35 \mathrm{eV}$, the activation energy for the $\mathrm{H}^{+}$ion discharge reaction decreases because of the increase in the $\mathrm{H}$-adatom subsurface $P t$ adsorption energy.

Acknowledgements-This work was financially supported by the Consejo Nacional de Investigaciones Científicas y Técnicas (Argentina). C. F. Z. is a member of the Programa de Desarrollo de Ciencias Básicas (Uruguay).

\section{REFERENCES}

1. A. Frumkin, in Advances in Electrochemistry and Electrochemical Engineering (Edited by P. Delahay and C. W. Tobias) Vol. 3, Interscience, New York (1963).

2. R. Parsons, Trans. Faraday Soc. 54, 1053 (1958).

3. H. Gerisher, Z. Phys. Chem. 8, 137 (1956)

4. B. E. Conway and J. O'M. Bockris, J. Chem. Phys. 26, 532 (1957).

5. J. Horiuti and M. Polanyi, Acta Physicochim. U.R.S.S. 2, 505 (1935).

6. J. O'M. Bockris, in Modern Aspects of Electrochemistry (Edited by J. O'M. Bockris) Vol. 1, Chap. 4, Butterworths, London (1954).

7. B. E. Conway and L. Bai, Electrochim. Acta 31, 1013 (1986).

8. B. V. Tilak and B. E. Conway, Electrochim. Acta 21, 745 (1976).

9. B. V. Tilak, C. G. Rader and B. E. Conway, Electrochim. Acta 22, 1167 (1977).

10. A. T. Hubbard, R. M. Ishikawa and J. Katekaru, $J$. electroanal. Chem. 86, 289 (1978).

11. N. Markovic, N. Marinkovic and R. Adzic, J. electroanal. Chem. 241, 309 (1988).

12. J. Clavilier, K. El Achi and A. Rodes, Chem. Phys. 141, 1 (1990).

13. F. T. Wagner and T. E. Moylan, Surf. Sci. 182, 125 (1987).

14. K. Bange, D. Grider and J. K. Sass, Surf. Sci. 126, 437 (1983).

15. I. M. Tidswell, N. M. Markovic and P. N. Ross, Phys. Rev. Lett. 71, 1601 (1993).

16. D. A. Harrington and B. E. Conway, J. electroanal. Chem. 221, 1 (1987).

17. L. Gao and B. E. Conway, Electrochim. Acta 39, 1681 (1994).

18. R. M. Torresi, O. R. Camara, C. P. de Pauli and M. C. Giordano, Electrochim. Acta 32, 1301 (1987).
19. T. Frenlink, W. Visscher and J. A. R. van Veen, Electrochim. Acta 40, 545 (1995).

20. H. Gerischer and W. Mehl, Z. Elektrochem. 59, 1049 (1955).

21. M. W. Breiter, H. Kammermaier and C. A. Knorr, Z. Elektrochem. 60, 37 (1956).

22. R. J. Nichols and A. Bewick, J. electroanal. Chem. 202 , 101 (1986).

23. A. Bewick, K. Kunimatsu, J. Robinson and J. W. Russell, J. electroanal. Chem. 132, 175 (1981).

24. A. Bewick and J. W. Russell, J. electroanal. Chem. 132 , 329 (1982).

25. A. Tadjeddine and A. Peremans, Abst. from Surface Science and Electrochemistry IUVSTA '94, p. 40 (L 24), San Benedetto del Tronto, 12-16 September (1994), Italy.

26. R. Hoffmann, J. Phys. Chem. 39, 1797 (1963).

27. A. B. Anderson and R. Hoffmann, J. Phys. Chem. 60 , 4271 (1974).

28. A. B. Anderson, J. Phys. Chem. 62, 1187 (1975).

29. G. Calzaferri, L. Forss and I. Kamber, J. Phys. Chem. 93, 5366 (1989).

30. G. Calzaferri and R. Hoffmann, J. Chem. Soc. Dalton Trans. 917 (1991).

31. M. Brändle and G. Calzaferri, Helvetica Chimica Acta 76, 924 (1993).

32. D. R. Lide, Ed. CRC Handbook of Chemistry and Physics, CRC Press, Boca Raton, FL, 1990-91.

33. L. Pauling, The Nature of the Chemical Bond, 3rd edn., Cornell University Press, Ithaca, New York, p. 45 (1992).

34. C. F. Zinola, G. L. Estiú, E. A. Castro and A. J. Arvia, J. Phys. Chem. 98, $1766(1994)$

35. G. Calzaferri and M. Brändle, QCMP 116, QCPE Bulletin, Vol. 12, No. 4 (1992).

36. G. L. Estiú, S. A. Maluendes, E. A. Castro and A. J. Arvia, J. electroanal. Chem. 284, 289 (1990).

37. G. L. Estiú, S. A. Maluendes, E. A. Castro and A. J. Arvia, J. Phys. Chem. 92, 2512 (1988)

38. K. Przybylski, J. Koutecky, V. Bonacic-Koutecky, P. von Ragué-Schleyer and M. F. Guest, J. Chem. Phys. 94, 5533 (1991).

39. J. P. Candy, P. Fouilloux and M. Primet, Surf. Sci. 72, $167(1978)$.

40. A. M. Baró, H. Ibach and H. D. Bruchmann, Surf. Sci. 88, $384(1979)$.

41. F. T. Wagner and P. N. Ross Jr. Surf. Sci. 160, 305 (1985).

42. J. O'M. Bockris and D. B. Matthews, Proc. Roy. Soc. A292, 479 (1966).

43. T. E. Felter, E. C. Sowa and M. A. Van Hove, Phys. Rev. B40, 891 (1989).

44. A. Wieckowski, J. Chim. Phys. 88, 1247 (1991).

45. J. Rogan, M. Lagos and I. K. Schuller, Surf. Sci. 318, L1165 (1994).

46. E. A. Moelwyn-Hughes, Physical Chemistry, 2nd Edn, Ch. 10, Pergamon Press, Oxford (1961). 